\section{Efficacy of dental prophylaxis (rubber cup) for the prevention of caries and gingivitis: a systematic review of literature}

\author{
A. Azarpazhooh ${ }^{1}$ and P. A. Main ${ }^{2}$
}

IN BRIEF

- For the prevention of caries in children, dental prophylaxis need not be provided either at a recall visit or before the application of topical fluorides.

- For the prevention of gingivitis in the general population, dental prophylaxis at recall appointments is not effective for the prevention or treatment of gingivitis.

- Dental prophylaxis remains of benefit for child management and for stain removal and aesthetic considerations.

\begin{abstract}
Background The purpose of this systematic review was to assess the efficacy of routine dental prophylaxis applied before professionally applied topical fluoride (PATF) or at a regular recall visit in the prevention of caries or gingivitis. Types of studies reviewed Ovid MEDLINE and its allied versions; CINAHL; Cochrane Library; EMBASE; Health and Psychosocial Instruments; HealthSTAR; International Pharmaceutical Abstracts; and ACP Journal Club were searched for English and Human articles from 1966 to 2007 for original in vivo English publications assessing rubber cup dental prophylaxis. In vitro studies, case series, case reports or letters to editors (not containing primary data), editorials, review articles and commentaries were excluded but were read to identify any potential studies. Results One hundred and eighty-nine articles were searched for relevancy resulting in six original studies that met our inclusion criteria. There was a unanimous agreement in four studies that a dental prophylaxis is not warranted before a PATF for caries prevention in children. A generalisation on dental prophylaxis before PATF cannot be applied to adolescents and adults. Available evidence (two other studies) fails to demonstrate any benefit in the prevention of gingivitis from further dental prophylaxis at interval used for recall examinations. Clinical implication To prevent caries in children, dental prophylaxis need not be provided either at a recall visit or before PATF. Dental prophylaxis at intervals of four months or more is not justified for the prevention of gingivitis in the general population.
\end{abstract}

\section{BACKGROUND}

Dental prophylaxis typically consists of placing pumice or an abrasive paste in a rubber cup and applying the paste to the clinical crowns of the teeth using rotating rubber cup at slow speed. This aims at the complete removal of plaque, salivary pellicle, materia alba and extrinsic stains found on the crowns of teeth to reduce and prevent future dental caries. The clinical protocol for performing a routine dental prophylaxis before professionally applied topical fluoride (PATF) was first advanced by Knutson. ${ }^{1}$ The rationale behind this was the belief that materia alba, plaque and other natural coatings on tooth surfaces

\footnotetext{
${ }^{1 *}$ Community Dental Health Services Research Unit and The Department of Endodontics, ${ }^{2}$ Department of Community Dentistry, Faculty of Dentistry, University of Toronto, Room \# 521A, 124 Edward Street, Toronto, Ontario, M5G 1G6, Canada

*Correspondence to: Dr Amir Azarpazhooh

Email:amir.azarpazhooh@dentistry.utoronto.ca
}

Online article number E14

Refereed Paper - accepted 23 March 2009

DOI: 10.1038/sj.bdj.2009.899

${ }^{\bullet}$ British Dental Journal 2009; 207: E14 acted as a barrier, inhibiting fluoride uptake and consequently reducing the clinical efficacy of the topical fluoride application., ${ }^{2,3}$ Many clinicians believe that the removal of the acquired pellicle, plaque and other substances adhering to the enamel by professionally applied prophylaxis results in a greater amount of fluoride contacting the enamel surface, thus enhancing the efficacy of a PATF, ${ }^{2,4}$ and an expected increase in the reduction in the incidence of caries. The removal of plaque can be effectively accomplished with a toothbrush. However, the belief is that the acquired pellicle, a thin organic layer adherent to the surface enamel, can only be removed by pumice or other abrasive prophylaxis. ${ }^{2}$ The role of bacterial dental plaque in the aetiology of gingivitis and periodontal disease has been well established. ${ }^{5}$ Part of the prevention of such conditions is based on limiting the accumulation of micro-organisms on the teeth and maintaining a flora that is consistent with periodontal health.

Three separate studies have evaluated the effect of dental prophylaxis before PATF on the amount of fluoride uptake by enamel in vivo by comparing professionally cleaned and uncleaned teeth. Tinanoff et $a .^{2}$ concluded that the acquired pellicle does not inhibit or retard the deposition of fluoride in the surface enamel. Bruun et al. ${ }^{4}$ agreed. Results demonstrated that plaque-covered teeth took up more than twice the amount of fluoride than was taken up by cleaned teeth. This suggested the presence of plaque and materia alba on teeth might even contribute to a greater uptake of fluoride through increasing the exposure time of enamel to the fluoride contained in the plaque. Steele et al. ${ }^{6}$ conducted a similar study with the addition of assessing the effect of tooth brushing and flossing before PATF. They found that tooth brushing and flossing before PATF resulted in higher retained fluorine [sic] concentrations in surface enamel than did prophylaxis either using a fluoridated or non-fluoridated prophylaxis paste.

These studies show that the flow of fluoride ions into the enamel is not inhibited by the presence of the acquired pellicle, plaque and other natural substances on the surface of teeth. However, these 
findings on the amount of fluoride uptake by enamel cannot be directly correlated with the clinical initiation and progression of caries.

The dental profession has, in the past, accepted that periodic dental prophylaxes result in beneficial consequences for the periodontal tissues. Thus, many providers include dental prophylaxis as a gingivitis prevention measure at each recall appointment. Studies in the 1970s demonstrated the frequent use (bimonthly) of dental prophylaxis preceded by a comprehensive oral hygiene instruction (OHI) session as a measure to improve gingival health among adolescents. ${ }^{7-10}$ However, more recent studies do not support the efficacy of the sole provision of the dental prophylaxis procedure for the prevention of gingivitis. ${ }^{11-14}$ In partial support, in an earlier Cochrane review, ${ }^{15}$ insufficient evidence of either beneficial or adverse effects of routine scaling and polishing was found. This was a review of different time intervals and was for periodontal health.

An earlier evidence-based report on oral hygiene practices states that dental prophylaxis or polishing (no scaling) is not warranted for periodontal disease prevention and is solely an aesthetic procedure. ${ }^{16}$ Others have issued statements on this practice. The American Dental Hygienists Association (ADHA) has promulgated two position papers that are relevant to this discussion, the first on polishing, ${ }^{17}$ in which they recommended polishing to be performed only as needed and not be considered a routine procedure, and a second on dental prophylaxis, ${ }^{18}$ in which they stated that "there is no evidence that supragingival scaling and coronal polishing have any therapeutic value'. The American Academy of Pediatric Dentistry (AAPD) has also addressed both prophylaxis and oral hygiene in Vision, Mission, Strategic Directions and Policies and Guidelines in their reference manual. ${ }^{19}$ The recommendations for 'oral prophylaxis and topical fluoride treatment' (noted as 'especially for children at risk for caries and periodontal disease') is to provide at 12-24 months throughout their childhood to age 18 years. The 'Clinical Guideline for The Role of Prophylaxis in Pediatric Dentistry' recommends that: ${ }^{19}$

\begin{tabular}{l|l|l|}
\hline \multicolumn{2}{|l}{ Table 1 Yield of the literature search } & Results \\
\hline$\#$ & Search history & 1,463 \\
\hline 1 & (Dental prophylaxis or tooth cleaning) in title or abstract & 100,890 \\
\hline 2 & (Caries or Gingivitis or Fluoride or acidulated phosphate fluoride or APF) in title or abstract & 579 \\
\hline 3 & 1 and 2 & 225 \\
\hline 4 & Remove duplicates from 3 & 207 \\
\hline 5 & Limit 4 to English publications & 189 \\
\hline 6 & Limit 5 to human studies & 189 \\
\hline 7 & Limit 6 to year = "1966 - 2007" & 23 \\
\hline 8 & Updating the search strategy \#1 to \#6 from 2007 to February 2009 & 212 \\
\hline 9 & Total included for Title/Abstract screening (\#7 and \#8) & 62 \\
\hline 10 & Included articles after Title/Abstract screening & 18 \\
\hline 11 & Included articles for critical appraisal at the full copy stage & 4 \\
\hline 12 & Secondary search from references & 22 \\
\hline 13 & Scored for critical appraisal (\#11 and \#12 above) & 10 \\
\hline 14 & Excluding those with experimental design of prophy application (for example, once a week) & 12 \\
\hline 15 & Critically appraised and scored & 5 \\
\hline 16 & Scored but not meeting routine prophylaxis criteria, see Table 5 & 10 \\
\hline
\end{tabular}

1. The dental prophylaxis should be used as part of a comprehensive prevention programme designed to improve children's ability to maintain their oral health. The use of dental prophylaxis should be considered as an educational tool to allay patient fears regarding the manipulation of oral tissues

2. A patient-appropriate dental prophylaxis should be performed when indicated, in conjunction with OHI, periodic oral examination visits and other indicated preventive care.

This evidence-based report seeks to assess the efficacy of routine dental prophylaxis applied before professionally applied topical fluoride (PATF) or at a regular recall visit for the prevention of caries or gingivitis for all patients. More specifically, the report attempts to answer the following focused questions: Does dental prophylaxis provided at recall appointments reduce caries increments, on its own or in combination with PATF, or improve gingival health?

Caries increment is the amount of new caries since the previous measurement in the sample of the study and is a measure of success or failure of the intervention. In order to find the most relevant answers to the above-mentioned questions, we assumed that any benefit in improved health outcomes must be both clinically (ie the smallest difference that clinicians and patients feel improves oral health or wellness) and statistically significant ( $p<0.05$ ); and if there is no benefit at the threshold of both clinical and statistical health improvement, then the procedure should not be used for that purpose. To correspond to conventional recall frequencies, we selected only the studies with prophylaxis given at a recall appointment at intervals of four months or more as our working definition of dental prophylaxis provided at recall appointments.

\section{METHOD}

\section{Literature search}

Literature searches of the 1966 to February 2009 database using Ovid MEDLINE and its allied versions; Cumulative Index to Nursing and Allied Health Literature; Evidence Based Medicine of Cochrane Central Register of Controlled Trials; Cochrane Database of Systematic Reviews; Database of Abstracts of Reviews of Effects; EMBASE; Health and Psychosocial Instruments; HealthSTAR; International Pharmaceutical Abstracts; and ACP Journal 


\begin{tabular}{|c|c|}
\hline \multicolumn{2}{|c|}{ Recommendation grades for specific clinical preventive actions } \\
\hline A & The CTF concludes that there is good evidence to recommend the clinical preventive action. \\
\hline B & The CTF concludes that there is fair evidence to recommend the clinical preventive action. \\
\hline c & $\begin{array}{l}\text { The CTF concludes that the existing evidence is conflicting and does not allow making a recommendation for or against use of the clinical preventive } \\
\text { action, however other factors may influence decision-making. }\end{array}$ \\
\hline D & The CTF concludes that there is fair evidence to recommend against the clinical preventive action. \\
\hline $\mathrm{E}$ & The CTF concludes that there is good evidence to recommend against the clinical preventive action. \\
\hline I & $\begin{array}{l}\text { The CTF concludes that there is insufficient evidence (in quantity and/or quality) to make a recommendation, however other factors may influence } \\
\text { decision-making. }\end{array}$ \\
\hline \multicolumn{2}{|r|}{$\begin{array}{l}\text { The CTF recognises that in many cases patient-specific factors need to be considered and discussed, such as the value the patient places on the clinical preventive } \\
\text { action, its possible positive and negative outcomes, and the context and/or personal circumstances of the patient (medical and other). In certain circumstances where } \\
\text { the evidence is complex, conflicting or insufficient, a more detailed discussion may be required. }\end{array}$} \\
\hline \multicolumn{2}{|c|}{ Levels of evidence - research design rating } \\
\hline I & Evidence from randomised controlled trial(s) \\
\hline II-1 & Evidence from controlled trial(s) without randomisation \\
\hline$\|-2$ & Evidence from cohort or case-control analytic studies, preferably from more than one centre or research group \\
\hline II-3 & Evidence from comparisons between times or places with or without the intervention; dramatic results in uncontrolled experiments could be included here \\
\hline III & Opinions of respected authorities, based on clinical experience; descriptive studies or reports of expert committees \\
\hline
\end{tabular}

Club were conducted. The subject heading 'dental prophylaxis' was combined with several key words: caries, fluoride, acidulated phosphate fluoride (APF), gingivitis or periodontal disease, harm, benefit, risk in title and/or abstract. The searches were limited to English language articles and human trials.

\section{Search strategy}

The articles were limited to original human studies assessing rubber cup dental prophylaxis. All other studies including in vitro studies, reviews, case series, etc were excluded but read to identify potential studies. Further articles were identified by reviewing the references and bibliographies of the retrieved articles. All articles at each stage were independently reviewed by both authors and discrepancies were resolved by consensus. The yield is summarised in Table 1. Twenty-two articles were retrieved, of which ten were not relevant to the focused question of this review and therefore did not meet our inclusion criteria, mainly because these articles had experimental designs of prophy application (ie prophylaxis) at a more frequent interval, for example once a week. The remaining 12 were scored using the Checklist to assess evidence of efficacy of therapy or prevention. ${ }^{20}$ This checklist consists of questions addressing ethics, study design, methodology and appropriateness of the results to the population of interest. The cut-off point for inclusion was set at 11 (out of a potential score of 16 for the checklist), resulting in a total of six articles. For each included article, the level of evidence was rated according to the classification developed by the Canadian Task Force on the Periodic Health Examination ${ }^{21}$ (Table 2).

\section{RESULTS}

With the use of the inclusion criteria, a total of four articles relating to dental prophylaxis and caries prevention and a total of two articles relating to dental prophylaxis and gingivitis prevention were selected for inclusion in the evidence table. The level of evidence and the recommendations for each article are listed in Tables 3 and 4. A further five articles (Table 5) are addressed since they are widely referred to, but in reality do not address routine prophylaxis as defined in this review.

\section{Dental prophylaxis and caries prevention}

We searched for studies that assessed the efficacy of bi-annual applications of fluoride on defs/DMFS/DMFT increments over a period of time. As seen in Table 3, Ripa et $a l .^{3}$ (randomised clinical trial, Level I) and Houpt et al..$^{22}$ (prospective, level II-1) carried out similar studies. In both studies, children (1,453 children aged 10-14 yrs in the former and 1,519 children aged 9-13 yrs in the latter) received twice yearly APF topical fluoride gel-tray treatment. Before the fluoride treatment, children were divided into three groups: Group 1 received prophylaxis with non-fluoridated paste, Group 2 brushed and flossed their own teeth under supervision, and Group 3 had no specific tooth cleaning procedure before the topical fluoride treatment. These children were followed up for three years in the former and for two years in the latter study. The results of both studies revealed no statistically significant differences in DMFS/DMFT increments between a PATF with or without a prior prophylaxis (grade of recommendation D/E; see Table 2)

Bijella et al. ${ }^{23}$ undertook a longitudinal clinical study (level II-1) to evaluate the effect of dental prophylaxis before the topical application of acidulated phosphate fluoride solution applied twice a year in 160 schoolchildren aged 7-10 yrs. These children were divided into three groups: Group I: control group, had no treatment; 


\begin{tabular}{|c|c|c|c|c|c|c|}
\hline $\begin{array}{l}\text { Author, } \\
\text { Date }\end{array}$ & Population & Intervention/Test & Control & Outcome & $\begin{array}{l}\text { Critical } \\
\text { appraisal } \\
\text { comments }\end{array}$ & $\begin{array}{l}\text { Level of evidence } \\
\text { recommendation }\end{array}$ \\
\hline $\begin{array}{l}\text { Ripa et al., } \\
1984^{3}\end{array}$ & $\begin{array}{l}1,453 \text { chil- } \\
\text { dren aged } \\
10-14 \text { yrs } \\
949 \text { in } \\
\text { sample at } \\
\text { year } 3 .\end{array}$ & $\begin{array}{l}\text { Efficacy of prior tooth cleaning on } \\
\text { bi-annual application of PATF over a } \\
\text { three-year period, biannual PATF. } \\
\text { Group II: brushed and flossed. } \\
\text { Group III: no prior cleaning. }\end{array}$ & $\begin{array}{l}\text { Positive control } \\
\text { Group I: } \\
\text { Biannual PATF } \\
\text { and prophy } \\
\text { with non- } \\
\text { fluoridated } \\
\text { paste }\end{array}$ & $\begin{array}{l}\text { DMFT increments for three years by Group } \\
\text { I: } 2.02 \pm 2.35 ; \text { II: } 1.98 \pm 2.07 ; \text { III: } 2.01 \pm 2.14 \\
\text { t test: NS (non significant) } \\
\text { Neither toothbrushing nor dental prophylaxis } \\
\text { before PATF enhanced the clinical efficacy of } \\
\text { PATF. }\end{array}$ & $\begin{array}{l}\text { Three year } \\
\text { results } \\
\text { Large loss to } \\
\text { follow-up in } \\
\text { year three. } \\
\text { No control } \\
\text { for outside } \\
\text { care stated. }\end{array}$ & $\begin{array}{l}\text { I E: } \\
\text { Good evidence to } \\
\text { recommend the } \\
\text { exclusion of dental } \\
\text { prophylaxis }\end{array}$ \\
\hline $\begin{array}{l}\text { Houpt } \\
\text { et al., } \\
1983^{22}\end{array}$ & $\begin{array}{l}1,519 \\
\text { children } \\
\text { aged } 9-13, \\
\text { Newark, } \\
\text { USA. }\end{array}$ & $\begin{array}{l}\text { Effect of various tooth-cleaning tech- } \\
\text { niques on the efficacy of semi-annual } \\
\text { PATF over two years (four times). } \\
\text { Group I: prophy before PATF. } \\
\text { Group II: cleaned own teeth prior to } \\
\text { PATF. } \\
\text { Group III: no prior cleaning. }\end{array}$ & $\begin{array}{l}542 \text { additional } \\
\text { children } \\
\text { examined and } \\
\text { received only } \\
\text { oral hygiene } \\
\text { instructions } \\
\text { but no PATF } \\
\text { as parental } \\
\text { permission was } \\
\text { not obtained. }\end{array}$ & $\begin{array}{l}\text { Two year DMFS increments by groups } \\
\text { I: } 2.05 \pm 3.4 \\
\text { II: } 2.48 \pm 4.2 \\
\text { III: } 2.14 \pm 3.4 \\
\text { Control: } 2.50 \pm 3.9 \\
\text { No significant differences in the groups }\end{array}$ & $\begin{array}{l}\text { Two year } \\
\text { study } \\
\text { No control } \\
\text { for outside } \\
\text { care stated }\end{array}$ & $\begin{array}{l}\text { II-1 D: } \\
\text { Fair evidence to } \\
\text { recommend the } \\
\text { exclusion of the } \\
\text { dental prophylaxis }\end{array}$ \\
\hline $\begin{array}{l}\text { Bijella } \\
\text { et al., } \\
1985^{23}\end{array}$ & $\begin{array}{l}160 \text { children, } \\
\text { Brazil }\end{array}$ & $\begin{array}{l}\text { Effect of toothbrushing and dental } \\
\text { prophylaxis before a PATF. } \\
\text { Group II: twice yearly PATF, prophy } \\
\text { with non-fluoridated paste. } \\
\text { Group III: twice yearly PATF, prior } \\
\text { tooth brushing with non-fluoridated } \\
\text { paste. }\end{array}$ & $\begin{array}{l}\text { Group I control, } \\
\text { no treatment }\end{array}$ & $\begin{array}{l}\text { DMFT/DMFS increments over } 18 \text { months by } \\
\text { group } \\
\text { I: } 3.9 / 9.2 ; \text { II: } 1.4 / 3.3 ; \text { III: } 1.4 / 2.4 \\
\text { Statistical difference between the control } \\
\text { group I and both groups II and III is stated in } \\
\text { article but no p values were given. Differences } \\
\text { between groups II and III were not significant. } \\
\text { Treatment provided } 64-72 \% \text { caries reduc- } \\
\text { tion. Dental prophylaxis before PATF does not } \\
\text { enhance the caries preventive effect of a PATF }\end{array}$ & $\begin{array}{l}18 \text { month } \\
\text { study } \\
\text { No control } \\
\text { for outside } \\
\text { care stated } \\
\text { No calcula- } \\
\text { tion of power. }\end{array}$ & $\begin{array}{l}\text { II-1 D: } \\
\text { Fair evidence to } \\
\text { recommend the } \\
\text { exclusion of the } \\
\text { dental prophylaxis }\end{array}$ \\
\hline $\begin{array}{l}\text { Johnston } \\
\text { et al., } \\
1995^{24}\end{array}$ & $\begin{array}{l}\text { High risk } \\
\text { children } \\
\text { Age } 6-7: \\
n=176 \\
\text { Age } 10-11: \\
n=153 \\
\text { Ontario }\end{array}$ & $\begin{array}{l}\text { Biannual (twice yearly) versus annual } \\
\text { with or without prophy to children } \\
\text { Age 6-7 (176) } \\
\text { Group I: (45) annual APF + no prophy } \\
\text { Group II: (45) annual APF + prophy } \\
\text { Group III: (39) biannual APF + no } \\
\text { prophy } \\
\text { Age 10-11 (153) } \\
\text { Group I: (33) annual APF + no prophy } \\
\text { Group II: (45) annual APF + prophy } \\
\text { Group III: (30) biannual APF + no } \\
\text { prophy }\end{array}$ & $\begin{array}{l}\text { Routine } \\
\text { practice. } \\
\text { Age 6-7 } \\
\text { Group IV } \\
\text { (47) biannual } \\
\text { APF + prophy } \\
\text { Age 10-11 } \\
\text { Group IV } \\
\text { (45) biannual } \\
\text { APF + prophy }\end{array}$ & $\begin{array}{l}\text { DMFS increments over three years by group } \\
\text { Age 6-7 (176) } \\
\text { Group I: } 3.82 ; \text { Group II: } 5.04 ; \text { Group III: } 3.53 ; \\
\text { Group IV: } 3.93 \\
\text { Covariate baseline defs and DMFS were sig- } \\
\text { nificant for three year defs + DMFS increment; } \\
p=0.01 \text {. Main effect (Prophy) } p=0.23 \\
\text { Age } 10-11 \text { (153) } \\
\text { Group I: } 2.57 ; \text { Group II: } 2.66 ; \text { Group III: } 2.80 ; \\
\text { Group IV: } 2.26 \\
\text { NS for interaction and main effects }\end{array}$ & $\begin{array}{l}\text { Three years } \\
\text { No control } \\
\text { for APF or } \\
\text { treatment at } \\
\text { family dentist }\end{array}$ & $\begin{array}{l}1 \mathrm{D} \\
\text { Fair evidence to } \\
\text { recommend the } \\
\text { exclusion of the } \\
\text { dental prophylaxis. }\end{array}$ \\
\hline
\end{tabular}

Group 2: twice yearly topical application of APF solution with prior professional prophylaxis with rubber cup and nonfluoride paste; and Group 3: twice yearly topical application of acidulated phosphate fluoride solution with prior toothbrushing with a non-fluoridated prophy paste. They followed the children for 18 months and concluded that the addition of a prior prophylaxis did not enhance the efficacy of the bi-annual application of fluoride. Results indicated that toothbrushing before the PATF may be slightly more effective than a prior prophylaxis in decreasing facio-lingual and proximal caries (grade of recommendation: D). ${ }^{23}$

Johnston and Lewis ${ }^{24}$ performed a randomised, three-year, community-based clinical trial of professionally applied APF gel involving the use and non-use of a prior dental prophylaxis and annual and biannual APF applications for highrisk children in age groups 6-7 $(\mathrm{n}=176)$ and 10-11 $(n=153)$ years initially. Their findings were consistent with all of the above studies; neither the provision of prior prophylaxis (as compared with non-use of a prior dental prophylaxis) nor bi-annual PATF resulted in statistically significant three-year reduction in mean caries increments (grade of recommendation: D).

\section{Dental prophylaxis and gingivitis}

The literature search revealed a limited number of studies evaluating the effects of dental prophylaxis on gingivitis prevention. Two articles addressed the issue of the benefit from routine prophylaxis provided at the recall appointment.
Persson et al. ${ }^{13}$ performed a randomised community-based trial (level I) to examine the efficacy of bi-annual dental prophylaxis for the prevention of gingivitis as measured by bleeding on probing, the gingival component of the Community Periodontal Index of Treatment Need (CPITN). The subjects were randomly assigned to either a control group (usual procedures) or four interventions with incrementally more complex preventive strategies: two-hour cognitive behavioural training (group 2), behavioural training plus weekly chlorhexidine rinse (group 3), behavioural training plus weekly chlorhexidine rinse plus semi-annual fluoride varnish (group 4), behavioural training plus weekly chlorhexidine rinse plus semi-annual fluoride varnish plus semiannual prophylaxis (group 5). 'The control 


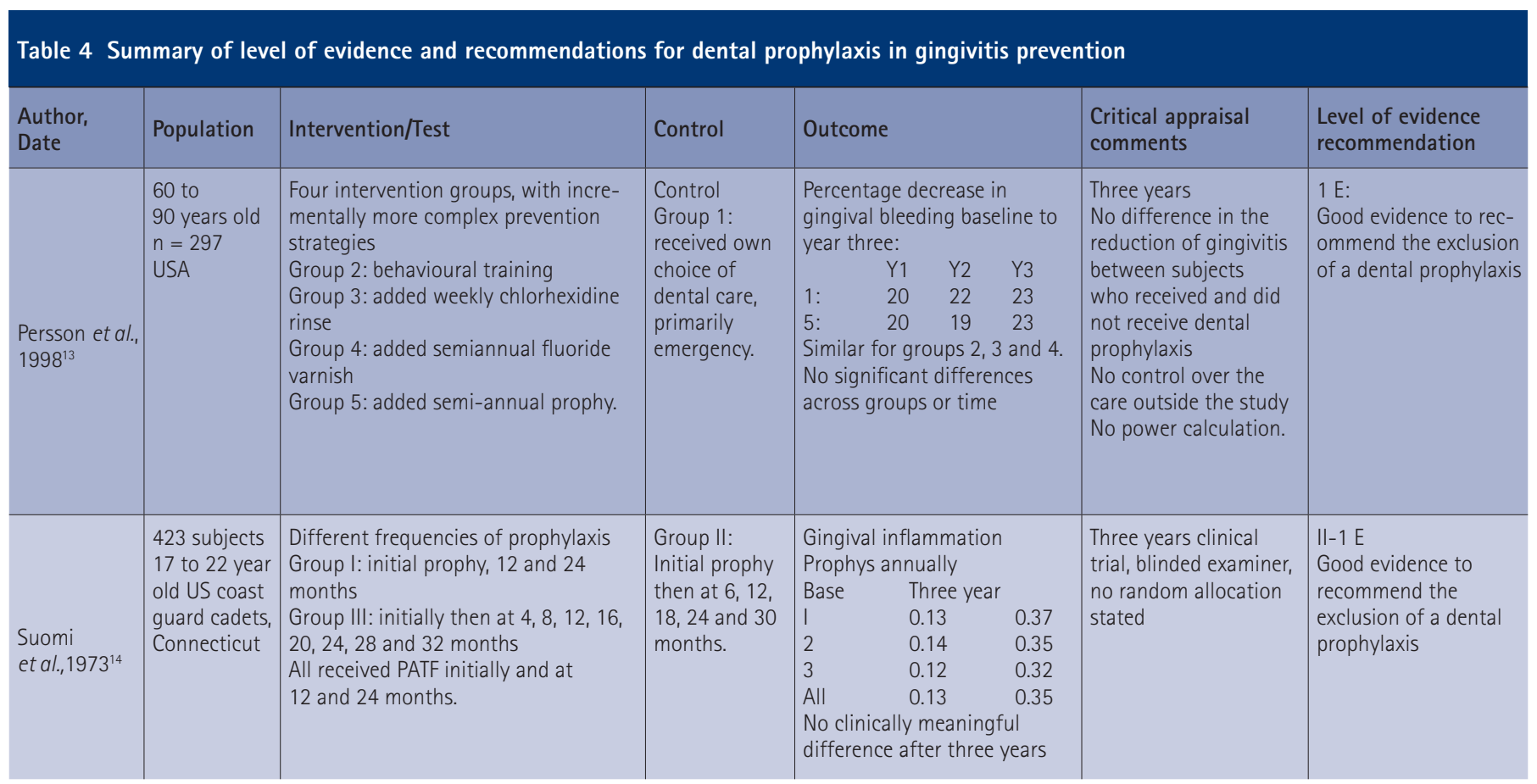

group received dental care as they preferred, primarily emergency care.' During their three-year investigation, no significant differences were found between the test group receiving a dental prophylaxis and the control group receiving no treatment (grade of recommendation: E). This study included a broad population mix, with subjects between the ages of 60 and 90 years old (mean age 72.8 ), allowing a recommendation to be made for the adult population.

Suomi et al. ${ }^{14}$ performed a longitudinal study (level II-1) on the gingival and periodontal health of cadets aged 17 to 22 over a three-year period on different frequencies of prophylaxes, ranging from once every year to three times per year. Initially these young men had better dental and general health than the general population for their age, with baseline gingival inflammation scores of $0.13(n=423)$. After three years, gingival inflammation scores in all three groups were $0.37,0.35$ and 0.32 respectively. They found neither statistical nor clinical differences among the three groups in relation to gingival inflammation, sulcus depth or attachment loss (grade of recommendation: E). These investigations further justify the recommendation for the exclusion of dental prophylaxis for the prevention of gingivitis. These studies provide the evidence that there is no therapeutic effect of dental prophylaxis for the prevention of gingivitis.

\section{DISCUSSION}

\section{Caries prevention}

All studies that investigated the efficacy of prior prophylaxis (polishing) when performing PATF have been carried out with children. Thus, the recommendation made can only be applied to children and a generalisation cannot be applied to adolescents and adults. Only one study considered other factors that may influence DMFS/ DMFT. Additional research to evaluate the efficacy of dental prophylaxis before PATF should be conducted on a larger scale with respect to sample size and age range, with all factors that might influence the clinical outcomes considered.

In 2002, Houpt ${ }^{25}$ also addressed the challenges of implementing change even when one recognises the necessity for change. He cites two examples, stating that he changed his prophylaxis protocol in the 1980s once clinical research demonstrated that it was not necessary to do a prophylaxis before topical fluoride application, and the changing protocols for topical fluoride application. He comments on the slow adoption of change in regard to the provision of fluoride in fluoridated areas. This editorial generated a flurry of letters on the need for prophylaxis, for the AAPD guidelines to more clearly define when not to use a procedure, for guidelines based on current disease patterns, for evidence to address cost-effective use of professionally applied therapies, and changes to (lengthening) the recall interval for low risk patients. ${ }^{26,27}$

In agreement with this, in a 1997 survey by Main et al., ${ }^{28}$ only $16 \%$ of the 1,276 dentists interviewed in Ontario, Canada were aware that it is not necessary to provide a prophylaxis before topical fluoride application to achieve maximum caries protection. It was estimated that $\$ 100$ million (1997 Canadian dollars) is spent annually on combined prophylaxis and PATF in children. The Canadian Universal Code system uses a system of units of 15 minutes as a basis for setting fees. Thus, if a procedure takes 15 minutes it would be one unit of time. Based on the 2007 fees we can allocate time to PATF and prophy. The amount of time (per procedure per person) allocated to polishing procedures, code 11101 , or $\$ 33.46$ in the 2005 Ontario Dental Association fee guide, was 15 minutes, while the time allocation for a PATF, code 12101, was the equivalent of just over 10 minutes at \$23.66. Total fee for providing both services, ie codes 11101 and 12101 was $\$ 57.12$ Canadian..$^{29}$ If the prophylaxis procedure were to be eliminated, up to 15 minutes of professional provider time and $\$ 33.46$ could be saved. Thus, the elimination of the routine use of dental prophylaxis before a professional topical fluoride application could result in considerable savings of oral health resources in both private and public practice locations. This would permit that time to be available 


\begin{tabular}{|c|c|c|c|c|c|}
\hline 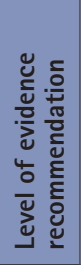 & 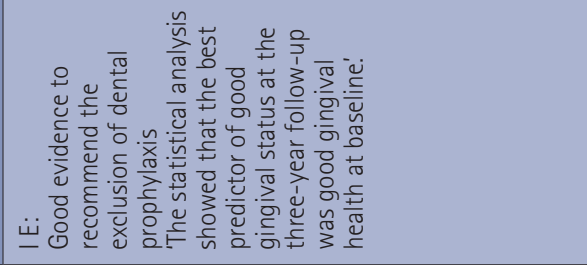 & 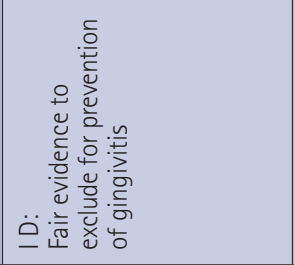 & 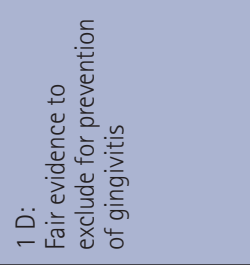 & 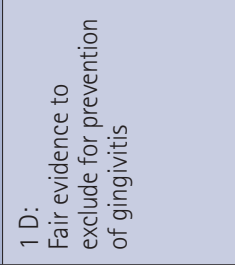 & 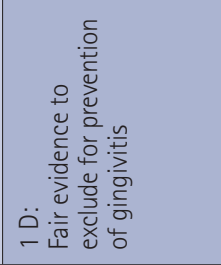 \\
\hline 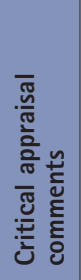 & 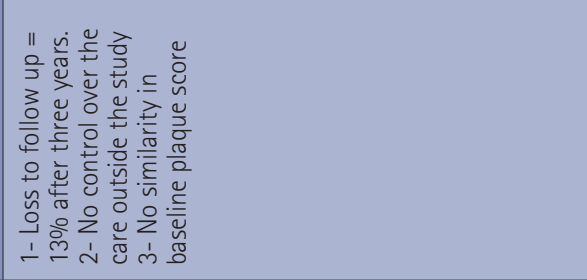 & 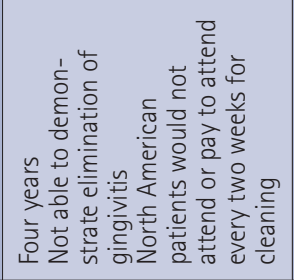 & 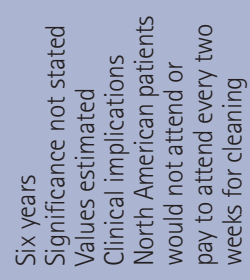 & 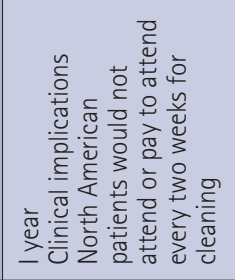 & 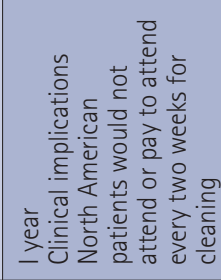 \\
\hline 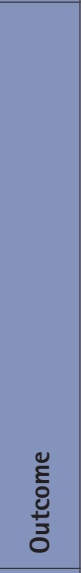 & 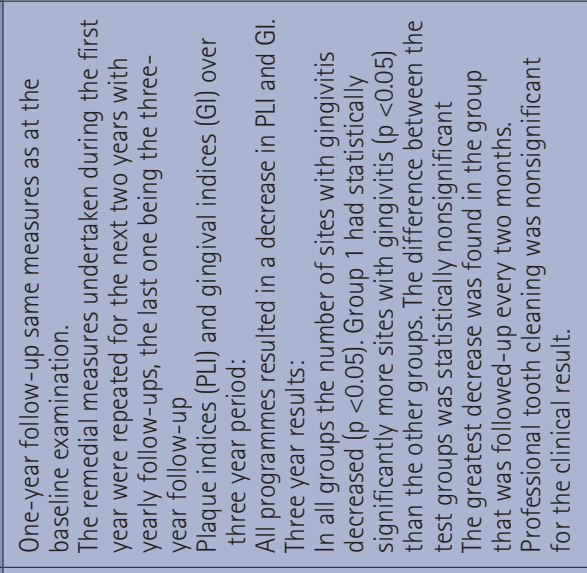 & 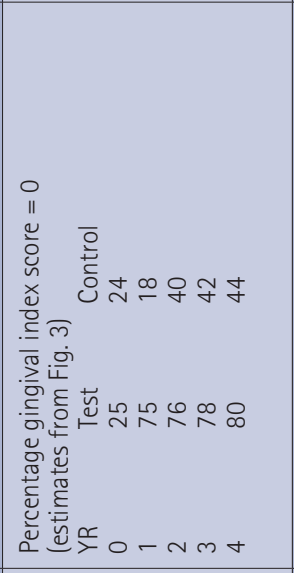 & 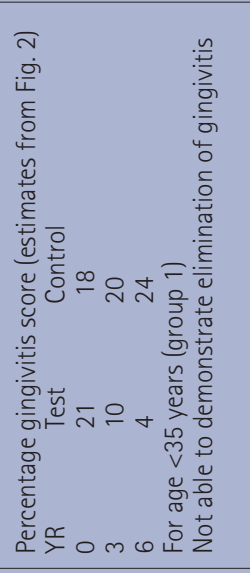 & 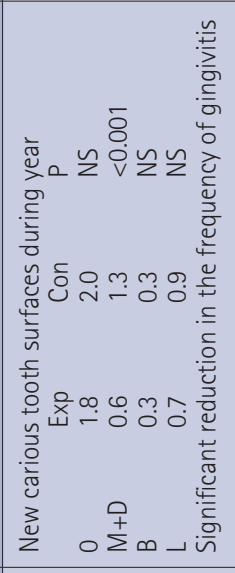 & 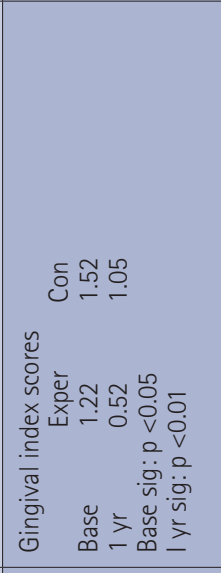 \\
\hline 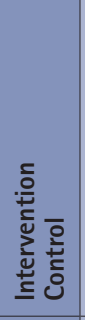 & 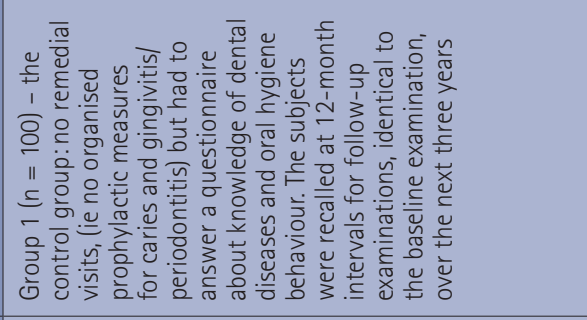 & 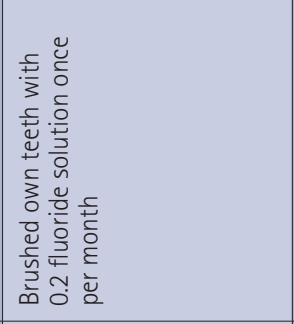 & 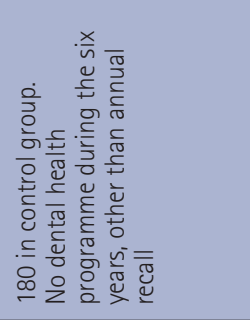 & 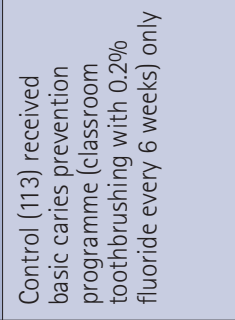 & 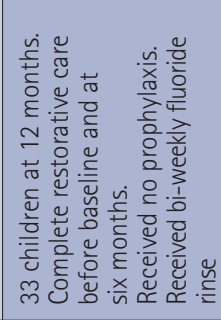 \\
\hline 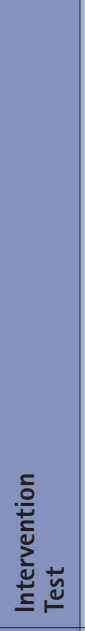 & 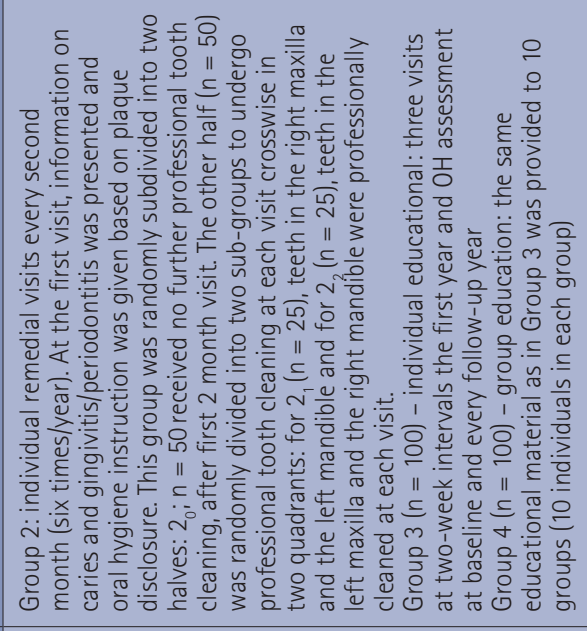 & 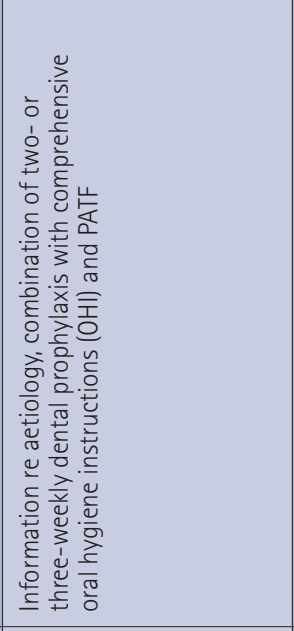 & 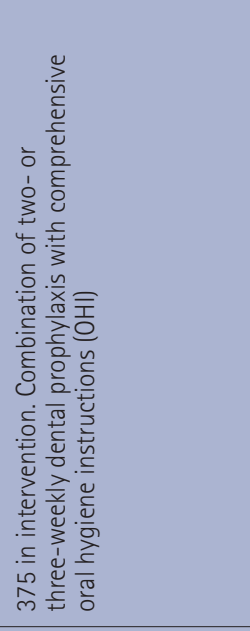 & 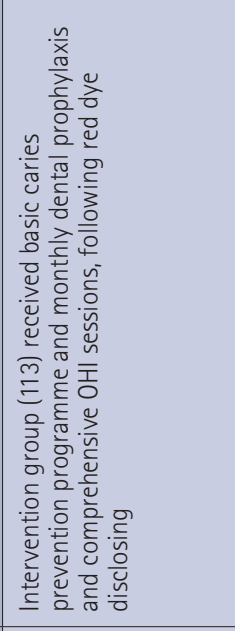 & 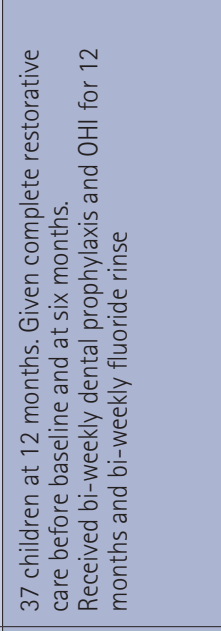 \\
\hline 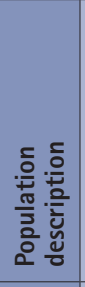 & 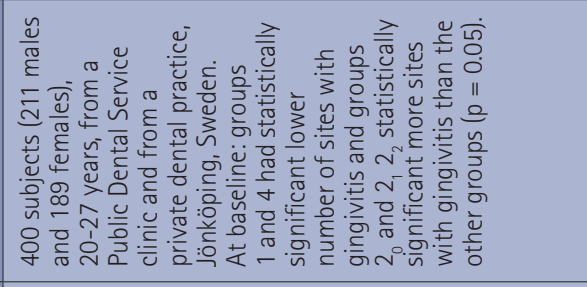 & 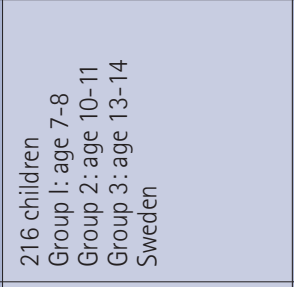 & 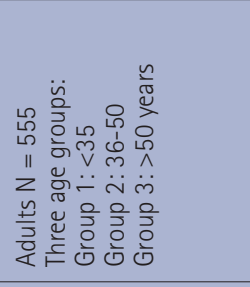 & 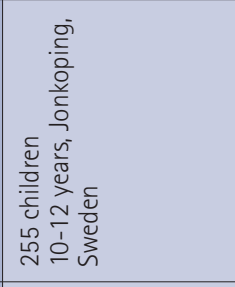 & 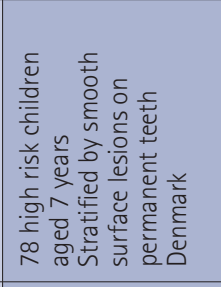 \\
\hline 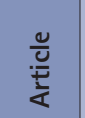 & 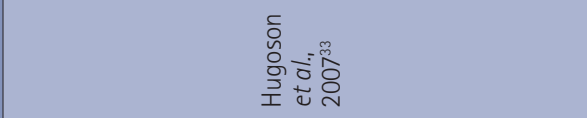 & 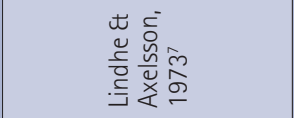 & 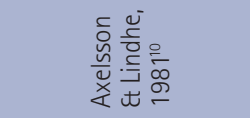 & 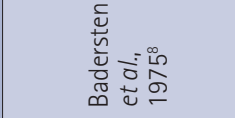 & 0.5 \\
\hline
\end{tabular}


for needed services in other people; as an example, more topical fluoride procedures could be performed, permitting more children to access and benefit from PATF for caries prevention.

Nainar ${ }^{30}$ confurms the economic savings as follows: "evidence-based caries prevention will likely result in a significant decline in preventive services revenues and create additional capacity in pediatric practices'. He suggests that the time saved by eliminating routine prophylaxis would permit paedodontists to provide services to more of the population: 'This economic impact will likely be absorbed by the current undersupply of pediatric dentists and by the reformulation of practice revenue streams'.

of interest are articles investigating evidence-based dental prophylaxis education in post-doctoral paediatric dentistry training programmes. ${ }^{31}$ Their findings that $74 \%$ of the training programmes (in 2001) routinely recommended dental prophylaxis for all recall patients, and that only 51\% of the training programmes had modified their teaching to substitute toothbrush prophylaxis, showed that only half of the post-doctoral programmes in the US taught evidence-based practice of dental prophylaxis for recall patients. They also surveyed AAPD members in active private practice in the six New England States in 2001 to assess their provision of dental prophylaxis. ${ }^{32}$ They found that 93\% routinely recommended dental prophylaxis for their recall patients (99\% for plaque, stain, and/ or calculus removal, 75\% for caries prevention, $82 \%$ before topical fluoride application, 58\% before sealant application, and $68 \%$ for behavioural modification).

\section{Gingival health}

Studies carried out in the 1970s and early 1980s evaluated the effects of controlled oral hygiene and dental prophylaxis performed at more frequent intervals, for example once a week, using two periodontal indices, the Plaque Index and the Gingival Index. These studies were carried out using both child and adult subjects (see Table 5). ${ }^{7-10,33}$ For example, while four of these studies ${ }^{7-10}$ found that frequent dental prophylaxis and comprehensive $\mathrm{OHI}$ resulted in a reduction of gingivitis, none was able to demonstrate elimination of gingivitis, which was their stated expectation. In fact gingivitis can develop when teeth are professionally cleaned at intervals greater than 48 hours. ${ }^{34}$ Moreover, the cost-effectiveness was not substantial enough to justify recommending the procedure for clinical use with all children. ${ }^{8}$

It should be noted that these studies applied both dental prophylaxis and comprehensive $\mathrm{OHI}$ together, making it difficult to determine which was responsible for any reduction in gingivitis. For an appropriate decision, it is essential to determine the effect of the dental prophylaxis procedure alone, without OHI. Studies that followed the methodology consistent with prophylaxis alone $\mathrm{e}^{11,12}$ concluded that there was no significant difference between the experimental population with prophylaxis and control population without prophylaxis with respect to the gingival health. This suggests that the reduced severity of gingivitis, seen in the earlier studies, was attributable to factors other than the dental prophylaxis. Therefore, in the majority of the adult population with gingivitis but without evidence of periodontitis, frequent dental prophylaxes are not warranted.

It should be noted that there are limited studies available on the efficacy of prophylaxis to improve gingival health carried out with adults and there is none carried out with children. Future studies should be conducted to investigate more clinically relevant intervals, ie limited to bi-annual or annual intervals and investigating the efficacy of dental prophylaxis treatment alone.

\section{CONCLUSION AND EVIDENCE- BASED RECOMMENDATIONS}

This evidence-based report seeks to assess the efficacy of routine dental prophylaxis applied before PATF or at a regular recall visit at intervals of four months or more, for the prevention of caries or gingivitis for all patients. The results of a thorough literature search and analysis of the above articles showed that prophylaxis before PATF does not improve caries prevention in children. This finding cannot be generalised to adolescents and adults due to a lack of such studies in these populations. Furthermore, dental prophylaxis provided at four monthly or six monthly intervals has been shown to have no therapeutic benefit in the prevention of gingivitis in adults. This review highlights the need for additional research on the therapeutic benefits of prophylaxis.

It is therefore recommended that:

- For the prevention of caries in children: dental prophylaxis need not be provided either at a recall visit or before the application of topical fluorides

- For the prevention of gingivitis in the general population: dental prophylaxis (rubber cup) at recall appointments (of intervals of four or six months) is not effective for the prevention or treatment of gingivitis.

It should be noted that there was a limited number of studies identified in the literature that answered the review questions (four for caries prevention and two for gingivitis prevention/treatment). Therefore, more studies should be conducted on a larger scale with respect to sample size and age range, with all factors that might influence the clinical outcomes considered. Moreover, each patient is unique. Therefore, dentists should appraise the applicability of these recommendations on the individual's basis based on their professional judgement. While the evidence does not support the application of dental prophylaxis for prevention of dental caries or gingivitis, it remains of benefit for child management in particular, and for stain removal and aesthetic considerations.

Declaration of interests: the authors have no declared financial interest.

1. Knutson J W. [Technic of application of sodium fluoride solution to the teeth]. Odontologia (Lima) 1967: 15: 102-103.

2. Tinanoff N, Wei S H, Parkins F M. Effect of a pumice prophylaxis on fluoride uptake in tooth enamel. J Am Dent Assoc 1974; 88: 384-389.

3. Ripa LW, Leske G S, Sposato A, Varma A. Effect of prior toothcleaning on bi-annual professional acidulated phosphate fluoride topical fluoride gel-tray treatments. Results after three years. Caries Res 1984; 18: 457-464

4. Bruun C, Stoltze K. In vivo uptake of fluoride by surface enamel of cleaned and plaque-covered teeth. Scand J Dent Res 1976; 84: 268-275.

5. Loe H, Rindom-Schiott C. The effect of suppression of the oral microflora upon the development of dental plaque and gingivitis. In McHugh W (ed) Dental plaque. 247-256. Edinburgh \& London: E \&t S Livingston, 1970

6. Steele R C, Waltner A W, Bawden J W. The effect of tooth cleaning procedures on fluoride uptake in enamel. Pediatr Dent 1982; 4: 228-233.

7. Lindhe J, Axelsson P. The effect of controlled oral hygiene and topical fluoride application on caries and gingivitis in Swedish schoolchildren. Community Dent Oral Epidemiol 1973; 1: 9-16.

8. Badersten A, Egelberg J, Koch G. Effect of monthly prophylaxis on caries and gingivitis in schoolchildren. Community Dent Oral Epidemiol 1975; 3: 1-4. 9. Poulsen S, Agerbaek N, Melsen B, Korts D, Glavind L, 
Rolla G. The effect of professional toothcleaning on gingivitis and dental caries in children after 1 year. Community Dent Oral Epidemiol 1976; 4: 195-199.

10. Axelsson P, Lindhe J. Effect of controlled oral hygiene procedures on caries and periodontal disease in adults. Results after 6 years. J Clin Periodontol 1981; 8: 239-248.

11. Listgarten M A, Schifter C C, Laster L. 3-year longitudinal study of the periodontal status of an adult population with gingivitis. $J$ Clin Periodontol 1985; 12: 225-238.

12. Glavind L. Effect of monthly professional mechanical tooth cleaning on periodontal health in adults. J Clin Periodontol 1977; 4: 100-106

13. Persson R E, Persson G R, Powell LV, Kiyak H A. Periodontal effects of a biobehavioural prevention program. J Clin Periodontol 1998; 25: 322-329.

14. Suomi J D, Smith L W, Chang J J, Barbano J P. Study of the effect of different prophylaxis frequencies on the periodontium of young adult males. J Periodontol 1973; 44: 406-410.

15. Beirne $P$, Worthington H V, Clarkson J E. Routine scale and polish for periodontal health in adults. Cochrane Database Syst Rev 2007; (4): CD004625.

16. Brothwell D J, Jutai D K, Hawkins R J. An update of mechanical oral hygiene practices: evidence-based recommendations for disease prevention. J Can Dent Assoc 1998; 64: 295-306.

17. American Dental Hygienists' Association. Position paper on polishing procedures.
Chicago, IL: ADHA, 1997.

18. American Dental Hygienists' Association. Position paper on the oral prophylaxis. Chicago, IL: ADHA, 1998.

19. American Academy of Pediatric Dentistry. Definitions, oral health policies, and clinica guidelines. Chicago, IL: AAPD, 2007-2008.

20. Azarpazhooh A, Mayhall J T, Leake J L. Introducing dental students to evidence-based decisions in dental care. J Dent Educ 2008; 72: 87-109.

21. Canadian Task Force on Preventive Health Care. Canadian Task Force methodology, levels of evidence - research design rating. Ottawa, Canada: Health Canada, 1997

22. Houpt M, Koenigsberg S, Shey Z. The effect of prio toothcleaning on the efficacy of topical fluoride treatment. Two-year results. Clin Prev Dent 1983 5: 8-10.

23. Bijella M F, Bijella V T, Lopes E S, Bastos J R. Comparison of dental prophylaxis and toothbrushing before topical APF applications. Community Dent Oral Epidemiol 1985; 13: 208-211.

24. Johnston D W, Lewis D W. Three-year randomized trial of professionally applied topical fluoride gel comparing annual and biannual applications with/ without prior prophylaxis. Caries Res 1995; 29: 331-336.

25. Houpt M. Real change is difficult. Pediatr Dent 2002; 24: 95.

26. Pittman J L. The need for dental prophylaxis
Pediatr Dent 2002; 24: 285

27. Tinanoff N. Decision making for preventive procedure Pediatr Dent 2002; 24: 534-535.

28. Main P A, Lewis D W, Hawkins R J. A survey of general dentists in Ontario, part II: knowledge and use of topical fluoride and dental prophylaxis practices. J Can Dent Assoc 1997; 63: 607, 610-617.

29. The Ontario Dental Association. ODA suggested fee guide for general practitioners, revised January 12007.

30. Nainar S M. Economic implications of evidencebased caries prevention in pediatric dental practice: a model-based approach. Pediatr Dent 2001; 23: 66-70.

31. Redford-Badwal D A, Nainar S M. Assessment of evidence-based dental prophylaxis education in postdoctoral pediatric dentistry programs. J Dent Educ 2002; 66: 1044-1048.

32. Nainar S M, Redford-Badwal D A. Survey of dental prophylaxes rendered by pediatric dentists in New England. J Contemp Dent Pract 2004; 5: 14-22.

33. Hugoson A, Lundgren D, Asklow B, Borgklint G. Effect of three different dental health preventive programmes on young adult individuals: a randomized, blinded, parallel group, controlled evaluation of oral hygiene behaviour on plaque and gingivitis. J Clin Periodonto/ 2007; 34: 407-415.

34. Lang N P, Cumming B R, Loe H. Toothbrushing frequency as it relates to plaque development and gingival health. J Periodontol 1973; 44: 396-405. 